\title{
Evaluation of cropping method for perennial ratoon rice
}

\section{(SALIBU) [version 1; peer review: 2 approved with}

\section{reservations]}

\author{
Masato Oda (D1), Huu Chiem Nguyen², Van Thao Huynh (iD)2 \\ ${ }^{1}$ Crop, Livestock and Environment Division, Japan International Research Center for Agricultural Sciences, Tsukuba, 305-8686, Japan \\ 2Environmental Sciences, Can Tho University, Can Tho, Vietnam
}

V1 First published: 30 Oct 2019, 8:1825

https://doi.org/10.12688/f1000research.20890.1

Second version: 23 Dec 2019, 8:1825

https://doi.org/10.12688/f1000research.20890.2

Latest published: 30 Sep 2020, 8:1825

https://doi.org/10.12688/f1000research.20890.3

\section{Abstract}

Background: Generally, the yield of ratoon rice is at most $50 \%$ of the main crop. However, a cropping method "SALIBU" achieved more yield than the main crop and could be used for the cultivation of perennial cropping. Although the SALIBU method is implementing 10 additional management practices to conventional method, the effect of each management practice is unclear. Therefore, we aimed to evaluate the effect size and the robustness of each management practice.

Methodology: We evaluated the effect size using an $\mathrm{L}_{16}$ orthogonal array design pot experiment. For the robustness, we duplicated the experiment under both standard and checked whether the practice shows the same effect size. The bad conditions were low plant density, no fertilization, continuous flooding water management, and late harvesting.

Results: The ratoon rice yield was proportional to the number of ratoon tillers used as in conventionally produced ratoon rice. Late cutting was most affected to the number of ratoon tillers. Importantly, this effect was reversed; the effect was positive under bad conditions, but was negative under standard conditions. Furthermore, late irrigation, a recommended management practice, had a robust negative effect on ratoon tillers and yield under both the conditions. Positive large effects were shown in the bad condition only.

Discussion: Our results show that the SALIBU cropping method includes practices with unstable, negative, or minimal effects. The practices have unstable effects should be clarifying the interaction with the condition. The practices that have negative effects should exclude. Using practice on small effect size should depend on a costbenefit analysis.

Conclusions: SALIBU will be acceptable to the Mekong Delta triple cropping rice cultivation without the additional practice of original

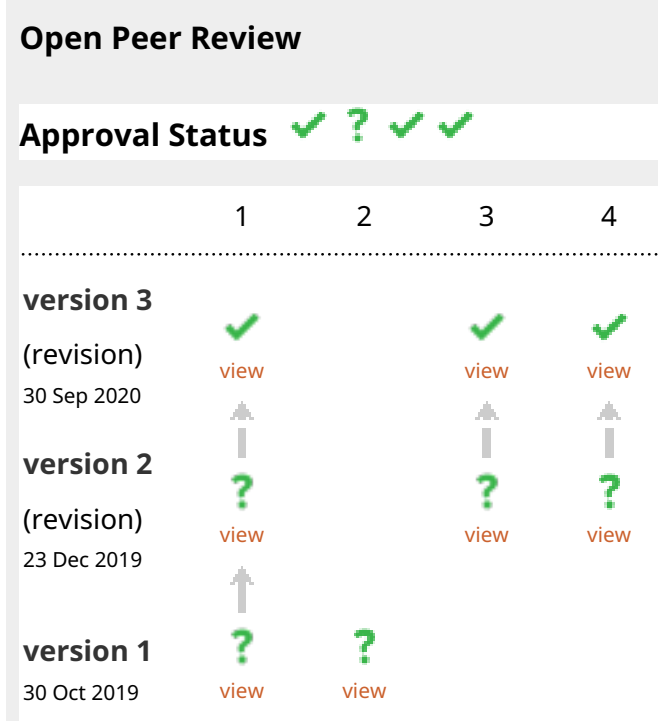

1. Triadiati Antono, IPB University, Bogor, Indonesia

2. Le Thi Hoa Sen, Hue University of Agriculture and Forestry, Hue, Vietnam

3. Chenfei Dong, Jiangsu Academy of Agricultural Sciences, Nanjing, China

4. Surajit Mondal ID, ICAR-Research Complex for Eastern Region, Patna, India

Any reports and responses or comments on the article can be found at the end of the article. 
SALIBU cropping method. However, further work is needed to clarify the interaction between late cutting and the cultivation condition, and on the negative effect of late irrigation.

\section{Keywords}

The Mekong Delta, Triple rice cropping, Methane mitigation, Row input, Sustainable, Taguchi method, Effect size

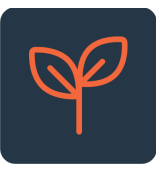

This article is included in the Agriculture, Food

and Nutrition gateway.

\section{Corresponding author: Masato Oda (oda.masato@affrc.go.jp)}

Author roles: Oda M: Conceptualization, Data Curation, Formal Analysis, Investigation, Methodology, Writing - Original Draft Preparation; Nguyen HC: Writing - Review \& Editing; Huynh VT: Data Curation, Investigation, Methodology, Resources, Writing Original Draft Preparation, Writing - Review \& Editing

Competing interests: No competing interests were disclosed.

Grant information: The author(s) declared that no grants were involved in supporting this work.

Copyright: ( $) 2019$ Oda M et al. This is an open access article distributed under the terms of the Creative Commons Attribution License, which permits unrestricted use, distribution, and reproduction in any medium, provided the original work is properly cited.

How to cite this article: Oda M, Nguyen HC and Huynh VT. Evaluation of cropping method for perennial ratoon rice (SALIBU) [version 1; peer review: 2 approved with reservations] F1000Research 2019, 8:1825 https://doi.org/10.12688/f1000research.20890.1

First published: 30 Oct 2019, 8:1825 https://doi.org/10.12688/f1000research.20890.1 


\section{Introduction}

\section{Ratoon rice}

Rice is usually an annual crop but can be renewed using the ratoon cropping method. Perennial cropping of rice requires less labor and water, while reducing climate risk and greenhouse gas emissions. Perennial rice cropping is a traditional cropping method but is rarely used because of the low yield. However, the additional yield achieved after harvesting the main crop has allowed its successful commercial application in the southern region of the United States of America and parts of southern China (Sacks, 2013). Most studies on ratoon rice have focused on additional yield, and the yield is at most $50 \%$ of the main crop (Negalur et al., 2017). A previous study reported a yield of up to $90 \%$ of the main crop using a special variety (PR23), but the fluctuations in yield were very large (Zhang et al., 2014).

\section{New approach using lower node}

Recently, a breakthrough in increasing yield was achieved in Indonesia. Rice has limited growth period during winter; therefore, rapid growth is the key to success of ratoon cropping. Moreover, ratoon cropping from higher nodes of rice is important, because the carbon can be accessible to the main crop culm (Balasubramanian et al., 1992). However, because tropical regions have no winter, the method used can be different. Fitri et al. (2019) looked at an updated method of traditional perennial rice cropping developed by Mr. Erdiman in 2010. The method was named "SALIBU," a portmanteau of the Indonesian words "SALIN" (replication) and "IBU" (mother). Using SALIBU, the same or higher yield than that of the main crop was achieved. The mechanisms inducing the high yield have not been well studied, but a possible reason is that lower nodes can extend new roots and improve nutrient uptake from the soil (Yamaoka et al., 2017). The implementation of SALIBU has been successful in different areas and at different elevations and groundwater levels in Indonesia (Fitri et al., 2019), and has recently spread to Myanmar (Yamaoka et al., 2017).

\section{Evaluation of management practices}

In some cases, the yield was less than $50 \%$ of the main crop yield (Hidayati et al., 2018). To adapt the SALIBU cropping method to areas with different growing conditions, we should evaluate the performance of each management practice, and modify the practices to suit the conditions. We aim to adapt the SALIBU method to direct seeding triple-cropping of rice in the Mekong Delta. Here, we found that the most effective (positive) management practice under poor conditions had an adverse effect (negative) under standard conditions. Furthermore, we found that the practice has a robust negative effect on the yields under both poor and standard conditions.

\section{Methods}

Evaluating each practice of a cropping method under different conditions is difficult because of the huge number of possible combinations. We have summarized the management practices of SALIBU method (Yamaoka et al., 2017) into four practices. We allocated those practices to two levels of an $\mathrm{L}_{16}$ orthogonal array (Taguchi, 1986) and conducted a pot experiment. To test robustness, the experiment was replicated under standard conditions and poor conditions, namely low plant density, no fertilization, continuous flood water management, and late harvesting: these conditions are known to reduce the yield of ratoon cropping of rice (Negalur et al., 2017). We analyzed the effect of each of the four practices on ratoon tillers and yield. Then, we evaluated the robustness of the effect of practices between the two conditions.

\section{Materials}

The pot experiment was conducted in a fine net house at Can Tho University (Can Tho city, Vietnam) from December 2018 to June 2019. We used $38 \mathrm{~cm} \times 58 \mathrm{~cm}$ wide and $30 \mathrm{~cm}$ high containers. All containers were filled up to $20 \mathrm{~cm}$ with paddy soil. The soil was collected from topsoil (about $25 \mathrm{~cm}$ ) of a paddy field at TL2 Hamlet, Thuan Hung village, Thot Not district, Can Tho city, Vietnam, just after natural flooding of the Mekong River and used on the day it was collected. The soil was well mixed in advance. Germinated seeds (Jasmin 85 variety from Can Tho University, popular in the Mekong Delta) were used. Jasmin is an Indica and has characteristics unsuitable for ratoon cropping of rice (Negalur et al., 2017). These disadvantages will amplify the effects of the practices. We used urea $(46 \% \mathrm{~N})$, single superphosphate $\left(16 \% \quad \mathrm{P}_{2} \mathrm{O}_{5}\right)$, and potassium chloride $\left(61 \% \mathrm{~K}_{2} \mathrm{O}\right)$ as fertlizers; the applied amount of those contents $\left(\mathrm{kg} \mathrm{ha} \mathrm{h}^{-1}\right)$ used for each treatment are given in the following section.

\section{Treatments}

SALIBU management consists of nine special management practices in addition to the conventional cropping management practice of rice transplanting (Yamaoka et al., 2017). The practice of early harvesting (physiological maturity; 25\% green color husk) is conventional in Mekong Delta triplecropping cultivation. The rest of the practices are as follows. (1) Pre-fertilization: $25 \mathrm{~kg} \mathrm{ha}^{-1} \mathrm{~N}$ and $46.75 \mathrm{~kg} \mathrm{ha}^{-1} \mathrm{P}_{2} \mathrm{O}_{5}$ at seven days before harvesting. (2) Cutting twice: all rice was harvested $25 \mathrm{~cm}$ above the ground, then cut again beneath the first node above ground on day seven (or day zero for control plants) after harvesting (rice straws were returned to the ground). The recommendation is to cut $3-5 \mathrm{~cm}$ above ground; we kept only the node below ground. (3) Late irrigation: irrigation was started on day 14 (or day seven for control plants) after harvesting (the water table was about $5 \mathrm{~cm}$ until irrigation started). (4) Adjusting: the practice consisted of (a) hand weeding, (b) dividing hills into two or three tillers and replanting to fill the space, (c) pushing the rice plants into the soil if the root came up on soil surface, (d) removing excess plants to keep original plant density, and (e) draining from day 29 to 43 after harvesting (though (e) is not "adjusting", it is technically inseparable because "adjusting" requires draining). We did the pot experiment using an $\mathrm{L}_{16}$ orthogonal array design. We set the pots randomly in the fine net house.

\section{Conditions}

The standard conditions were based on the standard of direct seeding triple rice cropping in the Mekong Delta: the plant density was $230 \mathrm{~kg} \mathrm{ha}^{-1}$ dry weight (about 173 seeds per pot), fertilizer was applied three times on day seven $\left(27.6 \mathrm{~kg} \mathrm{ha}^{-1} \mathrm{~N}\right.$, $\left.45.2 \mathrm{~kg} \mathrm{ha}^{-1} \mathrm{P}_{2} \mathrm{O}_{5}, 3.68 \mathrm{~kg} \mathrm{ha}^{-1} \mathrm{~K}_{2} \mathrm{O}\right), 20$ (36.7 $\left.\mathrm{kg} \mathrm{ha}^{-1} \mathrm{~N}\right)$, and 42 (27.6 kg ha ${ }^{-1} \mathrm{~N}, 3.68 \mathrm{~kg} \mathrm{ha}^{-1} \mathrm{~K}_{2} \mathrm{O}$ ) after seeding, with alternate wet 
and dry water management (15 to $5 \mathrm{~cm}$; from seven days after seeding to 10 days before harvesting).

The poor conditions were as follows: low plant density (nine plants per pot), no fertilization (except the pre-fertilization treatment), continuous flooding water management $(0$ to $5 \mathrm{~cm}$, from seven days after seeding to 10 days before harvesting), and late harvesting (seeded 10 days before the standard condition plants and harvesting on the same day of harvesting as the standard conditions). These conditions are known to negatively affect ratoon cropping of rice (Negalur et al., 2017).

\section{Analysis}

We recorded the number of plants and ratoon tillers at the harvesting time. We immediately oven-dried the sample then weighed the grain and straw. We analyzed the effect of the practices using the mean value and Cohens' $d$ effect size using the following formula (Cohen, 1992):

$$
d=\frac{M_{1}-M_{2}}{\sqrt{\frac{S D_{1}^{2}+S D_{2}^{2}}{2}}}
$$

where, $d$ is the effect size, $M_{1}$ is the mean of treatment, $M_{2}$ is the mean of un-treatment, and SD is standard deviation.

The $\mathrm{p}$ value of the significance test is affected by the sample size and cannot be used to assess the effect. Measuring effect sizes allows for evaluation involving variance and is not affected by the sample size. Data were processed using Microsoft Excel 2016.

\section{Results}

We examined the SALIBU management practices using an $\mathrm{L}_{16}$ orthogonal array design pot experiment and duplicated the experiment under standard and poor conditions. The ratoon rice yield was proportional to straw biomass, and the straw biomass was proportional to the number of ratoon tillers. Cutting twice had the highest effect, and the effect was reversed between the standard and poor conditions. Furthermore, late irrigation had a robust negative effect (Oda et al., 2019).

\section{Yield component}

The ratoon rice yield was proportional to straw biomass. The harvest index under poor conditions was higher than that under standard conditions (Figure 1). Importantly, straw biomass was proportional to the number of ratoon tillers under both conditions (Figure 2). The ratoon rice yield is determined by the number of ratoon tillers, and the relationship between the number of ratoon tillers and the yield is consistent with those reported in a previous study (Hidayati et al., 2018). The number of ratoon tillers was also in proportion to the number of plants under poor conditions (Figure 3), although it is important to note that under poor conditions, half of the pots had no ratoons.

\section{Effect of practices}

We examined the effect of management practices such as prefertilization, cutting twice, late irrigation, and adjusting on the number of ratoon tillers.

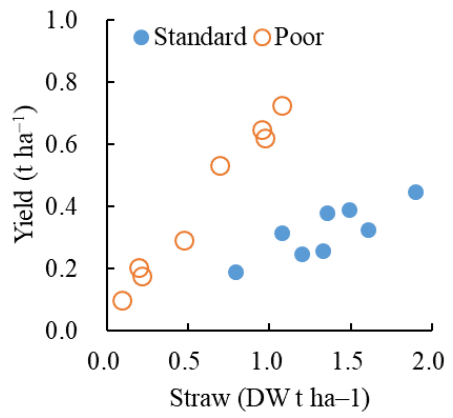

Figure 1. Straw biomass vs yield. DW, dry weight.

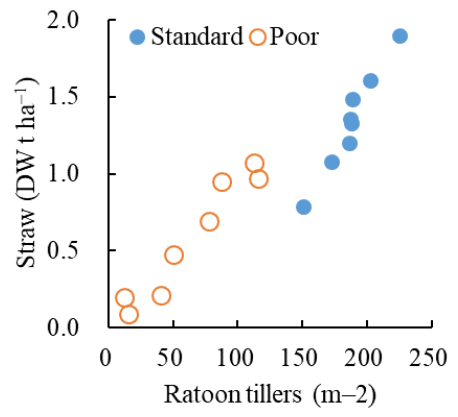

Figure 2. Ratoon tillers vs straw biomass.

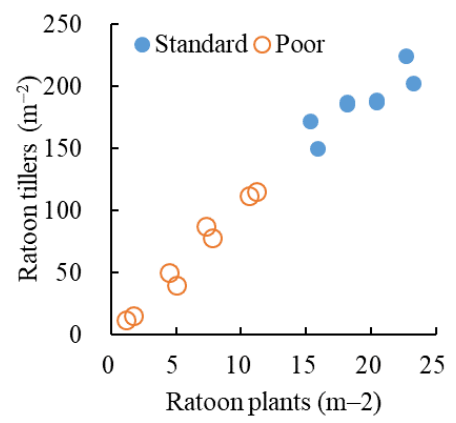

Figure 3. Ratoon plants vs Effective tillers.

Importantly, the effect of cutting twice was positive under poor conditions but was negative under standard conditions. In other words, there is an interaction between the practice and the condition. The average cutting heights (length of the first node) of the standard condition plants were $5.5 \mathrm{~cm}$ (cutting twice) and $4.0 \mathrm{~cm}$ (harvesting time), and those of the poor conditions were $6.8 \mathrm{~cm}$ and $3.0 \mathrm{~cm}$, respectively. The extensions of nodes were smaller under standard conditions than those under poor conditions. There is no consensus about the ideal cutting height (Negalur et al., 2017), although previous studies were not carried out using the SALIBU method.

Furthermore, late irrigation had a negative effect on the number of ratoon tillers under both conditions (Table 1). This might be a drawback of the pot experiment method due to decreased percolation; however, this is unlikely because the SALIBU method is successful in the lowlands (Fitri et al., 2019). 


\section{Robustness of effects}

Effect sizes provide an evaluation involving variance and are not affected by the sample size. The effect sizes of Cohen's $d<0.2,0.5,0.8$, and 1.2 , and $d>2.0$ correspond to small, medium, large, very large, and huge, respectively (Cohen, 1992: Sawilowsky, 2009). Figure 4 shows the relationship of the effect sizes between the conditions. The effect on ratoon tillers (Figure 4, left) and on yield (Figure 4, right) was similar but the effect on tillers was high under poor conditions. Pre-fertilization, cutting twice, and late irrigation had medium to large effect sizes. When the effect is near the 1:1 line, the effect is independent of the condition and is robust. A nonrobust effect signifies an interaction between the practice and the conditions. Positive large effects were shown under poor conditions only.

\section{Discussion}

The results of the effect size analysis show that the SALIBU cropping method includes practices that are unstable, negative,

\section{Table 1. Number of ratoon tillers by practice $\left(\mathrm{m}^{-2}\right)$.}

\begin{tabular}{|c|c|c|c|}
\hline Practice & & Standard & Poor \\
\hline Pre-fertilization & + & 187 & 112 \\
\hline \multirow{2}{*}{ Cutting twice } & - & 188 & 15 \\
\hline & + & 150 & 116 \\
\hline Late irrigation & - & 225 & 12 \\
\hline & + & 186 & 40 \\
\hline Adjusting & + & 189 & 87 \\
\hline & + & 172 & 50 \\
\hline
\end{tabular}

The mean value of the practices, $n=8$.

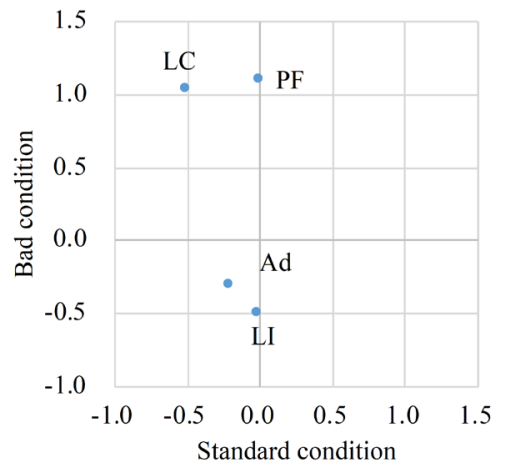

Ratoon tillers
\begin{tabular}{|c|c|c|c|c|c|}
\hline Effect size & $<0.2$ & 0.5 & 0.8 & 1.2 & $>2.0$ \\
\hline & Small & Medium & Large & Very large & Huge \\
\hline
\end{tabular}

Figure 4. Relation of effect size between the bad (poor) and standard conditions. PF, pre-fertilization; TC, cutting twice; LI, late irrigation; Ad, Adjusting and mid-term draining. Robust practices show similar effect sizes. Unstable practices, shown by differing effect sizes, have interactions with conditions.

or small. Improving these practices could improve the method.

\section{Reversed effect}

For the effects of SALIBU management on ratoon tillers, we found an interaction between cutting twice and the cultivation conditions (standard and poor). However, the poor conditions consisted of four factors, which are as follows: low plant density, no fertilization, continuous flooding water management, and late harvesting. Therefore, which of the factors interacts with cutting twice should be clarified.

\section{Negative effect}

Late irrigation has a robust negative effect. We can erase the negative effect by simply removing the practice. On the other hand, early irrigation may have a positive effect. In this way, an agricultural cropping method may include negative management practices if the effects are not evaluated. Our method is useful for screening positive practices in cropping methods.

\section{Small effect size practices}

Adjusting has a robust small effect and therefore, implementation should depend on a cost-benefit analysis. In contrast, prefertilization has a small effect under standard conditions, but has a large effect under poor conditions. The difference shows an interaction between the practice and the condition; however, this is reasonable because the plants under poor conditions were unfertilized.

\section{Evaluation of cropping method}

SALIBU is an excellent cropping method; however, its adaptability is unclear. Although evaluating each practice in a cropping method under different conditions is difficult because of the huge number of potential combinations, we overcame this difficulty by using an orthogonal array design pot experiment and duplicating the experiment under standard and poor conditions. Our results show that the SALIBU cropping method includes

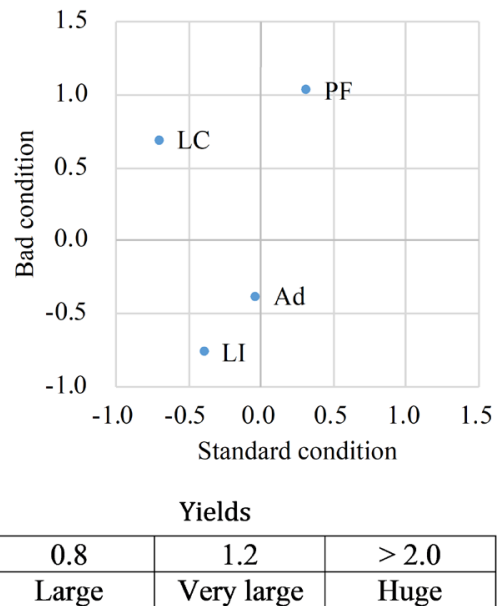

Yields 
practices with unstable, negative, or small effect sizes. Improving the use of these practices could improve the method. Practices with unstable effects should be used when known to have a positive effect under a specific condition. Negative effects can be excluded by excluding the practice. Small effect practices should be used depending on the outcome of a cost-benefit analysis. Perennial ratoon rice cropping will be possible for Mekong Delta triple rice cropping without the nine special management practices of the original SALIBU cropping method, because most of the effects of practices under standard conditions are small or negative.

\section{Conclusions}

We examined the management practices of the SALIBU ratoon rice cropping method. Cutting twice has a large effect on ratoon tillers and the effect reverses depending on the cultivation condition. Furthermore, late irrigation has a robust negative effect on the yield. Perennial ratoon rice cropping will be possible for the Mekong Delta triple rice cropping with the sole practice of harvesting rice near the ground; however, further work should be conducted with regard to perennial cropping of ratoon rice. The use of the orthogonal array design under different conditions is useful for future studies.

\section{Data availability}

Underlying data

Figshare: Salibu Effect. https://doi.org/10.6084/ m9.figshare.9937928.v1 (Oda et al., 2019)

Data are available under the terms of the Creative Commons Zero "No rights reserved" data waiver (CC0 1.0 Public domain dedication).

Acknowledgements

We thank the students who supported this work.
Balasubramanian R, Balakrishnan K, Manoharan S: Influence of Stubble Thickness, Carbohydrate Content and Leaf Senescence on Ratoon Rice. J Agron Crop Sci. 1992; 168(1): 10-12.

Publisher Full Text

Cohen J: A power primer. Psychol Bull. 1992; 112(1): 155-159.

PubMed Abstract | Publisher Full Text

Fitri R, Erdiman, Kusnadi N, et al.: SALIBU technology in Indonesia: an alternative for efficient use of agricultural resources to achieve sustainable food security. Paddy Water Environ. 2019; 17(3): 403-410.

Publisher Full Text

Hidayati N, Triadiati T, Anas I: Rooting System of Rice Cultivated Under System of Rice Intensification (SRI) Method Which Improving Rice Yield. HAYATI Journal of Biosciences. 2018; 25(2).

Reference Source

Negalur RB, Yadahalli GS, Chittapur BM, et al.: Ratoon Rice: A Climate and Resource Smart Technology. International journal of current microbiology and applied sciences. 2017; 6(5): 1638-1653.

Publisher Full Text

Oda M, Nguyen HC, Huynh VT: Salibu Effect. figshare. Dataset. 2019.

http://www.doi.org/10.6084/m9.figshare.9937928.v1
Sacks EJ: Perennial rice: challenges and opportunities. In: Batello, C. ed. Perennial Crops for food security. FAO. 2013; 16-26.

Reference Source

Sawilowsky SS: New effect size rules of thumb. J Mod Appl Stat Methods. 2009; 8(2): 597-599.

Publisher Full Text

Taguchi G: Introduction to quality engineering: designing quality into products and processes. 1986; [Accessed: 18 March 2014].

Reference Source

Yamaoka K, Htay KM, Erdiman, et al.: Increasing Water Productivity through Applying TropicalPerennial Rice Cropping System (SALIBU Technology) in CDZ, Myanmar. In: The 23rd ICID Congress: Towards A New Green Revolution 2.0. International Commission on Irrigation and Drainage (ICID). 2017.

Reference Source

Zhang S, Wang W, Zhang J, et al:: The Progression of Perennial Rice Breeding and Genetics. In: Perennial Crops for Food Security Proseedings of the FAO Expert Workshop. Food and Agriculture Organization of the United Nations (FAO). 2014.

Reference Source 


\section{Open Peer Review}

\section{Current Peer Review Status: ? ?}

\section{Version 1}

Reviewer Report 09 December 2019

https://doi.org/10.5256/f1000research.22984.r56890

(C) 2019 Sen L. This is an open access peer review report distributed under the terms of the Creative Commons Attribution License, which permits unrestricted use, distribution, and reproduction in any medium, provided the original work is properly cited.

\section{Le Thi Hoa Sen}

Hue University of Agriculture and Forestry, Hue, Vietnam

The abstract well conveys the research objectives, methods, key research results, discussion and conclusions. However, it needs to be shorter and more precise.

The study found very significant results for rice producers in three-crop rice-producing areas or in lowland areas that are vulnerable to natural disasters. However, the results will be more convincing if the collected data is analyzed more deeply, concerning the causes of fluctuating results. For instance, under poor conditions the effect of cutting twice was positive but negative under standard condition, why? What might be the causes? It needs further analyses of the results.

In addition, to be more practical and to validate research findings, experiments should be carried out one more time in the net house or in the real conditions.

Is the work clearly and accurately presented and does it cite the current literature? Yes

Is the study design appropriate and is the work technically sound?

Yes

Are sufficient details of methods and analysis provided to allow replication by others? Partly

If applicable, is the statistical analysis and its interpretation appropriate? Partly

Are all the source data underlying the results available to ensure full reproducibility? Yes

Are the conclusions drawn adequately supported by the results? 
Yes

Competing Interests: No competing interests were disclosed.

Reviewer Expertise: Adaptation to climate change in agriculture production.

I confirm that I have read this submission and believe that I have an appropriate level of expertise to confirm that it is of an acceptable scientific standard, however I have significant reservations, as outlined above.

Author Response 16 Dec 2019

Masato Oda, Japan International Research Center for Agricultural Sciences, Tsukuba, Japan

Thank you for your helpful comments. We shortened the abstract and made it more precise. We also changed the title too.

About the cutting twice, we are conducting an additional experiment. That is a portion of developing SALIBU for Mekong Delta triple cropping. We started the field experiment with suitable varieties.

Competing Interests: No competing interests were disclosed.

Author Response 26 Aug 2020

Masato Oda, Japan International Research Center for Agricultural Sciences, Tsukuba, Japan

We added the explanation for the Taguchi method as follows.

"The Taguchi method is a popular method to test the robustness of technologies in actual condition by artificial condition."

Competing Interests: No competing interests were disclosed.

Reviewer Report 02 December 2019

https://doi.org/10.5256/f1000research.22984.r55968

(C) 2019 Antono T. This is an open access peer review report distributed under the terms of the Creative Commons Attribution License, which permits unrestricted use, distribution, and reproduction in any medium, provided the original work is properly cited.

\section{Triadiati Antono}

Department of Biology, Faculty of Mathematics and Natural Sciences, IPB University, Bogor, Indonesia

1. The work is not yet clearly and accurately presented, nor does it cite the current literature. The literature review is limited, especially about salibu (definition, advantages, yield). The 
problems are not clear yet. What is the importance of this research (please use Pertanika et al., $2018^{1}$ as reference for example, because the article states the advantages.)

2. Because the methods (the treatments) are not clear and analysis does not use tools, the methods are not provided to allow replication by others.

3. Because the statistical analysis does not explain the tools used, it will be difficult to interpret easily

4. Results: did not need to state references.

5. Results: please just write down the results of the study, without mentioning the references.

6. Fig 1-3, Tab 1: please use statistical analysis to explain the results.

7. Discussion: explain the reasons for the results, use the references to discuss and compare research results. Please, use references for discussion.

\section{References}

1. Pasaribu PO, Triadiati, Anas I: Rice Ratooning Using the Salibu System and the System of RiceIntensification Method Influenced by Physiological Traits. Pertanika J. Trop. Agric. Sci.2018; 41

(2): 637-654

Is the work clearly and accurately presented and does it cite the current literature? Partly

Is the study design appropriate and is the work technically sound?

Yes

Are sufficient details of methods and analysis provided to allow replication by others? Partly

If applicable, is the statistical analysis and its interpretation appropriate? Partly

Are all the source data underlying the results available to ensure full reproducibility? Yes

Are the conclusions drawn adequately supported by the results?

Yes

Competing Interests: No competing interests were disclosed.

Reviewer Expertise: Plant physiology and plant ecophysiology.

I confirm that I have read this submission and believe that I have an appropriate level of 
expertise to confirm that it is of an acceptable scientific standard, however I have significant reservations, as outlined above.

\section{Author Response 16 Dec 2019}

Masato Oda, Japan International Research Center for Agricultural Sciences, Tsukuba, Japan

1. Thank you for your helpful comments. Our work has two aspects, evaluating SALIBU method, and adopting SAIBU to Mekong Delta Triple cropping. The former is means and the latter is the aim. We changed the title and improved the abstract and introduction.

2. Thank you so much for introducing the correct citation. We referred the paper but mistakenly typed another paper wrote by the same authors in the same year. We corrected that. Thanks again.

3. We guess that you mention about a table of the treatments. That is provided in "figshare". We added the link to the methods section. Please kindly point specifically if that is not enough.

4. For the tools, We show "Microsoft Excel 2016" and "the formula of the Cohens' $d$ effect size". That is enough to replicate our work. We provided the raw data by "figshare" and show the link. This is the regulation of F1000Research.

5. For the location of citation, F1000Research has no regulations. Citations in the result section are commonly seen. For example, a famous book, "Science Research Writing: A Guide for Non-Native Speakers of English", recommends no references should use unless essential in the discussion section.

6. We added a statistical analysis to Figures 1-3 and Table 1.

Competing Interests: No competing interests were disclosed. 
The benefits of publishing with F1000Research:

- Your article is published within days, with no editorial bias

- You can publish traditional articles, null/negative results, case reports, data notes and more

- The peer review process is transparent and collaborative

- Your article is indexed in PubMed after passing peer review

- Dedicated customer support at every stage

For pre-submission enquiries, contact research@f1000.com 